\title{
Knowledge of Dental Ethics and Jurisprudence Among Endodontists In Chennai, India: A Cross-Sectional Questionnaire Study
}

\author{
Nashwah Hinaz ${ }^{1}$ and Raghu Sandhya ${ }^{2}$ \\ ${ }^{1}$ Saveetha Dental College and Hospitals, Saveetha Institute of Medical \\ and Technical Sciences, Saveetha University, Chennai 600077, India \\ ${ }^{2}$ Reader, Department Of Conservative Dentistry and Endodontics, Saveetha Dental College and Hospitals, Saveetha \\ Institute of Medical and Technical Sciences, Saveetha University, Chennai 600077, India
}

\begin{abstract}
Ethics is a discipline that weighs the ideal human character and behavior in circumstances where the distinction should be made between what is right and wrong. Dental jurisprudence is put forth by each state's legislature. It describes the legal limitations and regulations related to the practice of dentistry. The aim of the present study was to understand the knowledge of dental ethics and jurisprudence among endodontists in Chennai, India. A cross-sectional questionnaire survey was conducted. A pilot study was conducted to validate the questionnaire. A specially designed questionnaire consisting of 21 close-ended questions. On assessing the results, it is seen that the majority of the endodontists are very much aware about the history and facts regarding ethics, jurisprudence. $45 \%$ of the endodontists are aware that the dentist act of India was started in the year 1948. It is seen that 54\% are aware that the code of ethics was given by DCI. They are also aware about the different principles of ethics. Almost 82\% endodontists are aware about the consent criteria and when it stands invalid. 73\% know that consent is for both the doctor and patient well-being. The study concludes that the majority of dental practitioners are aware of dental ethics but their knowledge on jurisprudence and COPRA needs to be increased.
\end{abstract}

\section{KEY WORDS: CONSENT, CONSUMER PROTECTION ACT, DENTAL PROFESSION, ETHICS, JURISPRUDENCE.}

\section{INTRODUCTION}

Dentistry as a profession has come a long way in recent years. It has grown from the stage of undifferentiated profession to the stage of advanced professionalism. During this period, dentistry has witnessed a number of changes and accepted new concepts. One of the most

\section{ARTICLE INFORMATION}

*Corresponding Author: sandhya.sdc@saveetha.com Received 15th June 2020 Accepted after revision 10th August 2020 Print ISSN: 0974-6455 Online ISSN: 2321-4007 CODEN: BBRCBA

Thomson Reuters ISI Web of Science Clarivate Analytics USA and Crossref Indexed Journal

\section{Clarivate
Analytics}

NAAS Journal Score 2020 (4.31) SJIF: 2020 (7.728)

A Society of Science and Nature Publication,

Bhopal India 2020. All rights reserved.

Online Contents Available at: http//www.bbrc.in/

Doi: http://dx.doi.org/10.21786/bbrc/13.7/85 important characteristics of the profession is following a Code of Ethics. Ethics is defined as a part of philosophy that deals with moral conduct and judgment. It is the philosophy of human conduct, a way of stating and evaluating principles by which problems of behavior can be solved(Kesavan et al., 2016).

Dental jurisprudence is put forth by each state's legislature. It describes the legal limitations and regulations related to the practice of dentistry, dental hygiene, and dental assisting (Peter, 2003). Dental ethics was laid by the members of the dental profession as a moral obligation to maintain a professional conduct. In 1976, Dental Council of India (DCI) laid the dentists (Code of Ethics) regulations. It was later revised in the year 2014. It is the duty of every registered dentist to read these regulations,

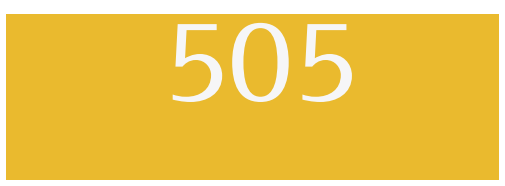


understand his responsibilities, and abide by the same (Kesavan et al., 2016). Ethics and morals are the basic ingredients of integrity, which then moulds character. Integrity is the commonality found in the professions of law, medicine, and dentistry and can be the determining factors for the degree of success of endodontists in the thin field of dentistry.

As endodontists it is extremely essential to understand and be aware of the ethics and jurisprudence in the field of dentistry. An endodontist should have acquaintance with the main provisions of these acts. He should know the responsibilities and precautions to be taken to avoid untoward happenings, including legal problems. He should also be familiar with his legal liabilities and the meaning of some terms used (Ahuja, 2019)(N et al., 2014; Ahuja, 2019). Therefore, the present study is a humble effort to evaluate the knowledge of dental ethics and jurisprudence among endodontists in Chennai so that training modules can be designed for safer and more effective delivery of dental care.

We have numerous highly cited publications on well designed clinical trials and lab studies (Govindaraju, Neelakantan and Gutmann, 2017; Azeem and Sureshbabu, 2018; Jenarthanan and Subbarao, 2018; Manohar and Sharma, 2018; Nandakumar and Nasim, 2018; Teja, Ramesh and Priya, 2018; Janani and Sandhya, 2019; Khandelwal and Palanivelu, 2019; Malli Sureshbabu et al., 2019; Poorni, Srinivasan and Nivedhitha, 2019; Rajakeerthi and Ms, 2019; Rajendran et al., 2019; Ramarao and Sathyanarayanan, 2019; Siddique and Nivedhitha, 2019; Siddique et al., 2019; Siddique, Nivedhitha and Jacob, 2019). This has provided the right platforms for us to pursue the current study. The aim of the present study is to understand the knowledge of dental ethics and jurisprudence among endodontists in Chennai, India.

\section{MATERIAL AND METHODS}

A cross-sectional questionnaire survey was conducted to assess the knowledge of dental ethics and jurisprudence among endodontists in Chennai city. The source of data was primary. A pilot study was conducted to validate the questionnaire and to get the required sample size. The questionnaire was pilot tested on a small group of fifty participants which included twenty nine postgraduates and twenty one endodontist practitioners, who were requested to complete it and to indicate any question that they found unclear. The results were tabulated based on the responses and evaluated.

Inclusion criteria: The participants should be a practising dentist. The clinic of the participants should be located in Chennai city The participants may be attached to a dental college either as a faculty or as a postgraduate student.

Table 1. Distribution of the answers given by the participants to the questions on knowledge of dental ethics and jurisprudence among endodontists.
QUESTIONS /OPTIONS
ANSTVER DISTRIBUTION (\%)

\section{When was the dentist act given:}

$\begin{array}{llc}\text { A. } & 1948 & (45.5 \%) \square \\ \text { B. } & 1956 & (18.2 \%) \\ \text { C. } & 1954 & (18.2 \%) \\ \text { D. } & \text { Don't know. } & (18.2 \%)\end{array}$

2. The dentists (code of ethics) regulation was given by:
A. Indian Council of Medical Research
B. Dental Council of India
$(13.6 \%)$
C. Indian Dental Association
$(54.4 \%) \square$
Don't know.

3. The dentists (code of ethics) regulation first came into force in:
A. 1948
$(22.7 \%)$
B. $\quad 1956$
$(22.7 \%)$
C. $\quad 1976$
$(22.7 \%) \square$
D. Don't know.

4. The dentists (code of ethics) regulation was revised in the year: 

A. 200
$(13.6 \%)$
B. 2015
$(4.5 \%)$
C. 2014
$(45.5 \%) \square$
D. Don't know.
$(35.4 \%)$

5. There are principles of ethics:
A. 3
B. 5
(4.6\%)
C. 6
$(31.8 \%) \square$
D. Don't know.
$(40.9 \%)$
(22.7\%)

6. One of the following is not a principle of ethics:
A. Veracity or truthfulness.
$(11.2 \%)$
B. Confidentiality.
$(9.1 \%)$
C. Punctuality.
$(72.7 \%) \square$
D. Don't know.
$(7 \%)$

7. Every dental surgeon should maintain his each patient's records for a minimum of:
A. 3 years.
$(42.9 \%) \square$
B. 5 years
$(38.1 \%)$
C. 2 years.
$(19 \%)$

8.It is unethical for a dental surgeon to refuse a treatment because the patient is HIV positive or suffering from any other contagious disease:
A. True
$(76.2 \%) \square$
B. False.
(34.2\%)
C. Don't know.
(9.5\%)

9.Consent is invalid when:
A. Given under $12-18$ years of age
$(81.8 \%) \square$
B. Given over 18 years of age
C. Don't know.
$(13.6 \%)$

10.What are consent forms for:
A. To protect the doctor
$(22.7 \%)$
B. To protect the patient
C. Both

11.Before starting the treatment do you inform the patient of all the treatment options available:
A. Yes
B. No 
12. Most common cause of endodontic treatment failures:
A. Instrument separation
(9.1\%)
B. Canal blockage
$(36.4 \%) \square$
C. Perforation.
$(54.5 \%)$

13. Main factor affecting failure of endodontic therapy:
A. Poor diagnosis.
$(9.1 \%)$
B. Radiographic misinterpretation.
$(9.1 \%)$
C. Improper treatment.
(9.1\%)
D. All of the above
$(72.7 \%) \square$

14. Causes of root perforations :
A. Weak, poor files
$(27.3 \%)$
B. Vigorous instrumentation
$(45.5 \%) \square$
C. Canal blockage.
$(27.3 \%)$

15. Do you give a detailed explanation of the procedure and explain the complications associated with local anaesthesia?
A. Yes.
B. No.
$(61.8 \%) \square$
$(38.2 \%)$

16. Do you encounter complications during or after injections?
A. Yes
$(66.7 \%) \square$
B. No.
$(33.3 \%)$

17. Most common type of complications encountered by dentists:
A. Syncope
B. Hematoma.
$(16.2 \%)$
C. Anaphylaxis
D. Failure of anesthesia

18.Are you aware of COPRA(Consumer Protection Act)1986?
A. Yes
$(71.4 \%) \square$
B. No
(28.6\%)

19. Is dental insurance mandatory in India ?
A. Yes.
(22.7\%)
B. No.
$(36.4 \%) \square$
C. Don't know.
$(40.9 \%)$ 
20. What is the compensation paid to the patient for wrong dental procedure?

$\begin{array}{ll}\text { A. } & \text { Rs } 1000-50000 . \\ \text { B. } & \text { Rs } 50000-100000 \\ \text { C. } & \text { More than Rs } 1,00,000 .\end{array}$

$(14.3 \%)$

$(47.6 \%) \square$

$(38.1 \%)$

21. Practice in a Medical and dental field is a risky and complicated profession?
A. Yes
$(84 \%) \square$
B. No
$(16 \%)$

Exclusion criteria: Dental practitioners who were not available to take the survey The clinic located outside Chennai city Dentists who were not willing to participate. Dentists who were not studying or practising endodontics. The study was conducted from December 2019 to January 2020 which included a specially designed questionnaire consisting of 21 close-ended questions. Sample size for the survey was 50. The first few questions consisted of the questions related to Knowledge of dental ethics and jurisprudence. The remaining section consisted of questions related to the complications faced during their practice in the clinic. The data obtained was analysed by descriptive and inferential statistics using SPSS.

\section{RESULTS AND DISCUSSION}

A total of 50 responses were obtained. 58\% responses were from the postgraduates and $42 \%$ of the respondents were practitioners. On assessing the results from Table 1 , it is seen that the majority of the endodontists were very much aware about the history and facts regarding ethics, jurisprudence. $45.5 \%$ endodontists were aware that the dentist act was given in the year 1948 and 54.4\% knew that the dentist code of ethics was given by the Dental council of India. There was a mixed response regarding the year in which the dentist code of ethics came into force, and only $22.7 \%$ were right in choosing the year 1976. $45.5 \%$ of them knew that dentists code of Ethics was revised in the year 2014 whereas 36.7\% weren't sure about the date. There are 5 principles of ethics and only $31.8 \%$ knew the right answer while $40.9 \%$ thought there are 6 principles. 72.7\% endodontists knew about the 5 principles of ethics. It is mandatory for a dentist to maintain his patients records and $42 \%$ endodontists were aware that records should be maintained for a minimum of 3 years. $76.2 \%$ believed that it is unethical to refuse treatment for a patient suffering from any contagious disease. Consent was considered invalid when given under the age of 12-18 years, $81.8 \%$ chose the right answer. $77.3 \%$ endodontists are well aware that consent forms are for both the doctor and the patient. 90.5\% knew that it is mandatory to inform the patient about the treatment and inform them about the various treatment options.
According to the endodontists, the most common cause of endodontic treatment failure was perforation 55\%, canal blockage 36.4\% and instrument separation 9.1\%. $72.2 \%$ of them chose that the main factor affecting failure of endodontic therapy was poor diagnosis, radiographic misinterpretation and improper treatment. $45.5 \%$ chose vigour instrumentation as the common cause of root perforation followed by weak poor files and canal blockage $27.3 \%$. Almost $81.8 \%$ of the practitioners explained about the procedures and complications associated with local anaesthesia. It is seen that $66.8 \%$ of them encountered complications during or after injections. Types of complications encountered by dentists were failure of anaesthesia 35.1\%, syncope $32.4 \%$, anaphylaxis and hematoma $32.4 \%$. $71.4 \%$ of the endodontists were aware about the Consumer Protection act, 1986 [COPRA]. 40.9\% did not know if dental insurance was mandatory or not in India .

Figure 1: The bar graph represents the association between the perception of risk in the medical and dentistry fields and the response of postgraduates (blue) and practitioners (red). $\mathrm{X}$ axis represents the response of participants regarding the risk in the field of dentistry; $\mathrm{Y}$ axis represents the number of participants. (Pearson's Chi square test, p value-0.001, $\mathrm{p}$ value $<0.05$, statistically significant. Majority of the postgraduates (48\%) and practitioners (36\%) considered that the medical and dental field is a risky and complicated profession in terms of medico legal aspect.

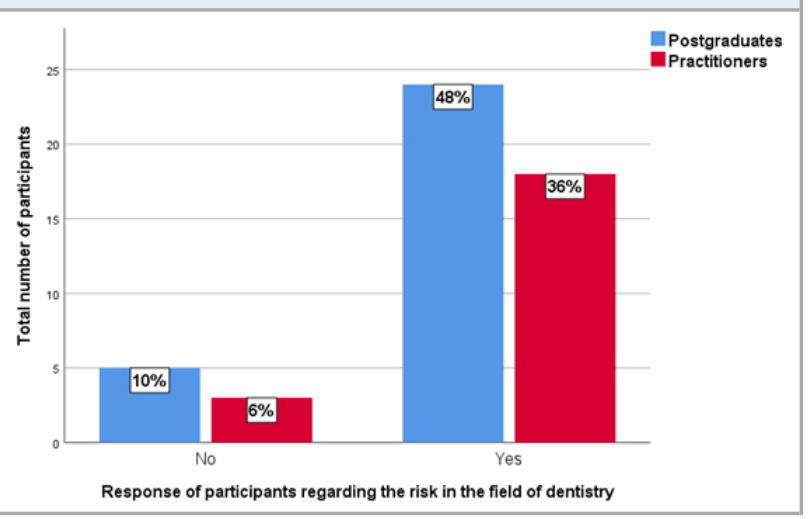


Almost $47.6 \%$ said that the compensation paid to the patient for wrong dental treatment procedure was Rs 5000-10000 and 38.1\% said that it was Rs. 1000-5000, however these values could change depending on the type of treatment that was done and the complications encountered. A large percentage of $84 \%$ endodontists believe that the medical and dental field was a risky and complicated profession. Figure 1 shows association between the risk in the field of dentistry and the response of postgraduates and practitioners. The analysis shows that $48 \%$ postgraduates and $36 \%$ practitioners agreed with a yes, for the presence of various risks in dentistry.

Dentistry is an art and science where new technology provides better treatment and convenience to both the patient and the dentist. Endodontics has emerged as a promising dental specialty to preserve the natural tooth to their function and esthetics and to avoid the need for extraction in many cases (Story, 2015). Previously, the doctor-patient relationship was considered as a trustworthy relationship. This relationship has deteriorated when the medical profession has been covered under the ambit of Consumer Protection Act (CPA) after its enactment in 1986. In CPA, patients were considered as consumers and doctors as health service providers. Due to the enactment of CPA, doctors have to become more vigilant and provide good ethical treatment to patients. On the other hand, frivolous complaints are filed against doctors regarding negligence by some deceitful patients for monetary benefits out of the case. Ultimately, there is continuous degradation of the doctorpatient relationship in the modern times(Yadwad and Gouda, 2005). Dentists have a profound responsibility and follow codes of conduct to act in the best interest of the patient. It is a patient's right that they might accept or reject the advice from the dentist. The vital concern of every patient is that they should be treated as a human being, i.e., as the unique and individual person. Any circumstances causing lack of duty amount to negligence and may give a chance to a patient to proceed in the court of law. The dentist must be aware of the legal provisions regarding negligence and CPA (Story, 2015)(Chaturvedi, 2007; Story, 2015)(Yadwad and Gouda, 2005).

A clinician performs various endodontic procedures like pulpotomy, pulpectomy, regenerative procedures, and post and core restorations. During such procedures, mistakes or errors could occur at any stage and the treatment might go wrong (Ramugade and Sagale, 2018). For every therapeutic, medicinal, or surgical procedure, consent of the patient is mandatory in eyes of the law for major (18 years and above) as well as the minor. For minor patients, i.e., below 18 years of age, consent of parents is a must. When written consent is not obtained, the patient may put an allegation on the dentist of negligence, trespassing his/her privacy, or breach of morality and decency (Khare and Saxena, 2018; Ramugade and Sagale, 2018). Proper diagnosis is very important for initiating any treatment. Sometimes, the diagnosis is ambiguous, and in an emergency situation, treatment has to be started. For proper endodontic diagnosis, case history and various vitality tests play a major role. Referred pain may also lead to wrong diagnosis in some cases(Koyess and Fares, 2006) .Treating the wrong tooth without proper diagnosis or valid written consent is considered as neglect (Koyess and Fares, 2006; Kaufmann, 2014). The consent should be obtained for any radiography mentioning the nature of radiation, dose, and risk and benefits of scanning (Wright, 2012).

Prescribing antibiotic prophylactically for infection control at the operated site or distant site is the dentist's responsibility. The dentist must evaluate all local and general factors which may increase the infection risk. There is no recommendation to prescribe antibiotics randomly. Antibiotics can be indicated to manage local infections or to prevent severe infection in the near future (Pippi, 2011). Failure to record the case details, not prescribing or medicating high-risk patients accordingly, is considered as negligence when found to be life-threatening (Robinson and Tambyah, 2017). For procedures involving endodontic therapy, radiographic documentation is mandatory. Multiangulated radiographs help in the best analysis of the tooth and root canal anatomy. Role of a specialist endodontist must be considered, especially when the patient demands, for the management of difficult cases, calcified canals, retreatment cases, teeth requiring post and core, endodontic surgery cases, or mentally and medically compromised patients (Caplan, Reams and Weintraub, 1999). When the dentist does any work beyond his/her qualification, skills, or expertise, and if any mishap occurred, he/she will be held liable for the act of negligence (Anju et al., 2020). The basic principle of endodontics is isolation, and the best method to do is by rubber dam application. In endodontics, it is considered as a standard of care. Thus avoid complications and life-threatening emergency, it is better to adopt the practice of applying rubber dam regularly in every case(Venkataraghavan et al., 2011; Chaudhry, 2013; Reddy et al., 2014; Yadav et al., 2015; Anju et al., 2020)

In clinical situations, the operator must obtain the informed consent of the patient mentioning all possible complications such as file breakage or perforation. Instrument separation in the root canal or beyond apex during the treatment would be considered as the procedural error or mishap in the literature; however, hiding the present mishap situation from the patient amounts to negligence (Premnath and John, 2015). A dentist must be well trained in diagnosis to justify the chosen treatment plan, well trained to explain the prognosis of the diseased tooth, well equipped to perform procedures with good infection control, skilled enough to avoid endodontic mishaps. A good clinician with an ethical practice will not only safeguard oneself but also deliver the best possible treatment to the patients seeking oral health. 


\section{CONCLUSION}

The present study indicates that the knowledge of dental ethics and jurisprudence among the endodontists of Chennai was mediocre. We have to address this issue in a practical and meaningful manner. Endodontists should be more aware about the ethics in their field and always keep in mind the safety of themselves and their patients.

Conflict of Interest: There were no conflicts of interest as declared by the authors.

\section{ACKNOWLEDGEMENTS}

The authors thank everyone who enabled us to carry out this study.

\section{REFERENCES}

Ahuja, B. S. (2019) 'The Revised Code of Dental EthicsShort Communication', World Journal of Advanced Scientific Research. World Journal of Advanced Scientific Research, 2, pp. 1-38.

Anju, V. et al. (2020) 'ACCIDENTAL INGESTION OF AN ENDODONTIC FILE: A CASE REPORT AND CLINICAL REVIEW', Journal of Research in Dentistry, p. 66. doi: 10.19177/jrd.v7e4201966-71.

Azeem, R. A. and Sureshbabu, N. M. (2018) 'Clinical performance of direct versus indirect composite restorations in posterior teeth: A systematic review', Journal of conservative dentistry: JCD, 21(1), pp. 2-9. Caplan, D. J., Reams, G. and Weintraub, J. A. (1999) 'Recommendations for endodontic referral among practitioners in a dental HMO', Journal of Endodontics, pp. 369-375. doi: 10.1016/s0099-2399(06)81174-X. Chaturvedi, A. (2007) 'Consent - Its Medico-legal Aspects', Medicine Update (Volume 17, 2007), pp. 883-883. doi: 10.5005/jp/books/12086_153.

Chaudhry, Z. (2013) 'A Remarkable Rare Case of Fractured Endodontic Instrument in Periradicular Region Compressing Inferior Alveolar Nerve', International Journal of Medical and Dental Sciences. doi: 10.19056/ ijmdsjssmes/2013/v2i1/86740.

Govindaraju, L., Neelakantan, P. and Gutmann, J. L. (2017) 'Effect of root canal irrigating solutions on the compressive strength of tricalcium silicate cements', Clinical oral investigations, 21(2), pp. 567-571.

Janani, K. and Sandhya, R. (2019) 'A survey on skills for cone beam computed tomography interpretation among endodontists for endodontic treatment procedure', Indian journal of dental research: official publication of Indian Society for Dental Research, 30(6), pp. 834-838.

Jenarthanan, S. and Subbarao, C. (2018) 'Comparative evaluation of the efficacy of diclofenac sodium administered using different delivery routes in the management of endodontic pain: A randomized controlled clinical trial', Journal of conservative dentistry: JCD, 21(3), pp. 297-301.

Kaufmann, R. (2014) 'Re: Failure of Root Canal Treatment Misdiagnosed as Neuropathic Pain', Journal . jcda.ca, 80, pp. e28-e28.

Kesavan, R. et al. (2016) 'Knowledge of dental ethics and jurisprudence among dental practitioners in Chennai, India: A cross-sectional questionnaire study', Journal of Orofacial Sciences, p. 128. doi: 10.4103/09758844.195915.

Khandelwal, A. and Palanivelu, A. (2019) 'Correlation Between Dental Caries And Salivary Albumin In Adult Population In Chennai: An In Vivo Study', Brazilian Dental Science, 22(2), pp. 228-233.

Khare, A. and Saxena, V. (2018) 'Acuity of morality in dental practice management', Journal of Dental Research and Review, p. 3. doi: 10.4103/jdrr.jdrr_4_18.

Koyess, E. and Fares, M. (2006) 'Referred pain: a confusing case of differential diagnosis between two teeth presenting with endo-perio problems', International Endodontic Journal, pp. 724-729. doi: 10.1111/j.1365-2591.2006.01139.x.

Malli Sureshbabu, N. et al. (2019) 'Concentrated Growth Factors as an Ingenious Biomaterial in Regeneration of Bony Defects after Periapical Surgery: A Report of Two Cases', Case reports in dentistry, 2019, p. 7046203.

Manohar, M. P. and Sharma, S. (2018) 'A survey of the knowledge, attitude, and awareness about the principal choice of intracanal medicaments among the general dental practitioners and nonendodontic specialists', Indian journal of dental research: official publication of Indian Society for Dental Research, 29(6), pp. 716-720.

Nandakumar, M. and Nasim, I. (2018) 'Comparative evaluation of grape seed and cranberry extracts in preventing enamel erosion: An optical emission spectrometric analysis', Journal of conservative dentistry: JCD, 21(5), pp. 516-520.

N, D. A. et al. (2014) 'Knowledge, attitude \&t practices regarding Ethics \& Law amongst medical and dental professionals in Rajasthan - A Questionnaire study', IOSR Journal of Dental and Medical Sciences, pp. 102-109. doi: 10.9790/0853-1354102109.

Peter, S. (2003) Essentials of Preventive and Community Dentistry.

Pippi, R. (2011) 'Antibiotic prophylaxis: reasoned choice and not casual use', Annali di stomatologia. CIC Edizioni internazionali, 2(3-4), p. 1.

Poorni, S., Srinivasan, M. R. and Nivedhitha, M. S. (2019) 'Probiotic strains in caries prevention: A systematic review', Journal of conservative dentistry: JCD, 22(2), pp. 123-128.

Premnath, P. and John, J. (2015) 'Knowledge attitude and practice toward preventive dental care among dental professionals in Chennai', Journal of Education 
and Ethics in Dentistry, p. 20. doi: 10.4103/09747761.178023.

Rajakeerthi, R. and Ms, N. (2019) 'Natural Product as the Storage medium for an avulsed tooth - A Systematic Review', Cumhuriyet Dental Journal, 22(2), pp. 249256.

Rajendran, R. et al. (2019) 'Comparative Evaluation of Remineralizing Potential of a Paste Containing Bioactive Glass and a Topical Cream Containing Casein Phosphopeptide-Amorphous Calcium Phosphate: An in Vitro Study', Pesquisa brasileira em odontopediatria e clinica integrada, 19(1), pp. 1-10.

Ramarao, S. and Sathyanarayanan, U. (2019) 'CRA Grid - A preliminary development and calibration of a paper-based objectivization of caries risk assessment in undergraduate dental education', Journal of conservative dentistry: JCD, 22(2), pp. 185-190.

Ramugade, M. and Sagale, A. (2018) 'A review of medicolegal considerations of endodontic practice for general dental practitioners', Journal of International Society of Preventive and Community Dentistry, p. 283. doi: 10.4103/jispcd.jispcd_206_18.

Reddy, M. S. R. et al. (2014) 'Emergency management of a dental foreign body ingestion using rigid esophagoscopy - A clinical case report', Journal of Pierre Fauchard Academy (India Section), pp. 125-128. doi: 10.1016/j.jpfa.2015.01.002.

Robinson, A. N. and Tambyah, P. A. (2017) 'Infective endocarditis - An update for dental surgeons', Singapore Dental Journal, pp. 2-7. doi: 10.1016/j. sdj.2017.09.001.

Siddique, R. et al. (2019) 'Qualitative and quantitative analysis of precipitate formation following interaction of chlorhexidine with sodium hypochlorite, neem, and tulsi', Journal of conservative dentistry: JCD, 22(1), pp. 40-47.

Siddique, R. and Nivedhitha, M. S. (2019) 'Effectiveness of rotary and reciprocating systems on microbial reduction: A systematic review', Journal of conservative dentistry: JCD, 22(2), pp. 114-122.

Siddique, R., Nivedhitha, M. S. and Jacob, B. (2019) 'Quantitative analysis for detection of toxic elements in various irrigants, their combination (precipitate), and para-chloroaniline: An inductively coupled plasma mass spectrometry study', Journal of conservative dentistry: JCD, 22(4), pp. 344-350.

Story, R. D. (2015) 'Medico-legal aspects of dental treatment of the ageing and aged patient', Australian Dental Journal, pp. 64-70. doi: 10.1111/adj.12285.

Teja, K. V., Ramesh, S. and Priya, V. (2018) 'Regulation of matrix metalloproteinase-3 gene expression in inflammation: A molecular study', Journal of conservative dentistry: JCD, 21(6), pp. 592-596.

Venkataraghavan, K. et al. (2011) 'Accidental ingestion of foreign object: Systematic review, recommendations and report of a case', The Saudi Dental Journal, pp. 177-181. doi: 10.1016/j.sdentj.2010.10.007.

Wright, B. (2012) 'Contemporary medico-legal dental radiology', Australian Dental Journal, pp. 9-15. doi: 10.1111/j.1834-7819.2011.01653.x.

Yadav, R. et al. (2015) 'Accidental aspiration/ingestion of foreign bodies in dentistry: A clinical and legal perspective', National Journal of Maxillofacial Surgery, p. 144. doi: 10.4103/0975-5950.183855.

Yadwad, B. S. and Gouda, H. (2005) 'Consent-Its medico legal aspects', JAPI. japi.org, 53, pp. 891-894. 